\title{
PENGARUH PELAYANAN ASUHAN KEPERAWATAN TERHADAP KEPUASAN PASIEN DI DI RUMAH SAKIT
}

\author{
Samuel Pangihutan Sitompul
}

Prodi Sarjana Ilmu Keperawatan, Fakultas Keperawatan Universitas Sumatera Utara.

\section{E-mail sitompulsamuel244@gmail.com}

\section{PENDAHULUAN}

Definisi pelayanan kesehatan yaitu suatu konsep yang dipakai dalam pemberian layanan kesehatan terhadap masyarakat. Pelayanan kesehatan juga diartikan sebagai konsep yang diterapkan untuk memberikan layanan dengan jangka waktu lama dan terus dilakukan kepada publik dan masyarakat.

Pelayanan kesehatan menurut Depkes RI adalah upaya untuk menyelenggarakan perorangan atau bersama-sama dalam organisasi untuk mencegah dan meningkatkan kesehatan, memelihara serta menyembuhkan penyakit dan juga memulihkan kesehatan perorangan, kelompok, keluarga dan ataupun publik masyarakat.

Penurunan jumlah pasien merupakan salah satu indikasi dari ketidakpuasan pasien pada pelayanan puskesmas walaupun tidak signifikan dalam membuktikan kepuasan atau ketidak puasan pasien. Rumah sakit memiliki kebijakan mutu dalam memberikan pelayanan prima yang berfokus pada kepuasan pelanggan, keluarga dan karyawan. Kebijakan tersebut dilaksanakan dengan cara meningkatkan kompetensi karyawan,memberikan pelayanan yang ramah, cepat, tepat dan akurat, memberikan kemudahan informasi pelayanan kepada pelanggan. Kebijakan tersebut sudah dimiliki oleh puskesmas, namun pada kenyataannya masih terdapat pasien yang mengeluh pada layanan rumah sakit terutama pasien rawat inap yang mengeluh pada layanan keperawatan.

Keadaan kurangnya kepuasan pasien terjadi kerena tuntutan kebutuhan pasien semakin meningkat namun tidak diiringi dengan perbaikan tindakan perawat. Layanan keperawatan dan kepuasan pasien menjadi indikator keberhasilan penyelenggaraan pelayanan kesehatan di rumah sakit. Kepuasan pasien akan terpenuhi bila pelayanan yang diberikan telah sesuai dengan harapan mereka. Apabila pelayanan yang diberikan belum sesuai dengan harapan pasien maka pasien akan merasa tidak puas. Perawat harus mampu memberikan pelayanan keperawatan yang optimal sesuai standar pelayanan keperawatan yang telah ada. Hal tersebut dikarenakan kepuasan pasien merupakan indikator keberhasilan pelayanan keperawatan. 


\section{PEMBAHASAN}

\section{a. Pelayanan Kesehatan}

Pelayanan kesehatan di rumah sakit sangat ditentukan oleh peran dari sumber daya manusia baik tenaga kesehatan maupun tenaga non kesehatan, tenaga kesehatan yang paling banyak di rumah sakit adalah perawat. Peran dan tugas perawat dalam pelayanan kesehatan dipuskesmas cukup dominan. Perawat memberikan pelayanan perawatan kepada pasien selama 24 jam setiap harinya1.Pelayanan keperawatan di rumah sakit merupakan salah satu faktor penentu dalam meningkatkan kualitas pelayanan, pelayanan yang baik akan memberikan kepuasan kepada pasien.

Asuhan keperawatan yang bermutu merupakan asuhan manusiawi yang diberikan kepada pasien, yang memenuhi standar dan kriteria profesi keperawatan, sesuai dengan standar dan kualitas yang diharapkan rumah sakit, serta mampu mencapai tingkat kepuasan dan memenuhi harapan pasien, perawatlah pertama kali mengetahui kondisi pasien setiap saat, karena perawat berada di sisi pasien selama 24 jam. Praktik keperawatan untuk memenuhi harapan pasien sesuai dengan standar praktik keperawatan yang dikeluarkan oleh Persatuan Perawat Nasional Indonesia tentang regestrasi tenaga kesehatan, bahwa setiap tenaga kesehatan harus lulus uji kompetensi, yaitu suatu proses untuk mengukur pengetahuan, keterampilan, dan sikap tenaga kesehatan atau keperawatan. Perawat dalam menjalankan profesinya harus memenuhi standar profesi, dan berdasarkan kemampuan melaksanakan asuhan keperawatan yang meliputi: pengkajian, penetapan diagnosa keperawatan, perencanaan, pelaksanaan tindakan keperawatan, serta evaluasi keperawatan.

A.A Maulana (2013) menyatakan sistem pelayanan kesehatan mempunyai tujuan antara lain yaitu:

1. Promotif, atau memelihara dan meningkatkan kesehatan hal ini sangat dibutuhkan seperti pada peningkatan gizi.

2. Preventif, atau pencegahan terhadap orang yang mempunyai resiko terhadap penyakit yang terdiri dari:

3. Preventif primer: Adalah tersusun dari program pendidikan seperti imunisasi, penyediaan nutrisi yang baik.

4. Prventif Sekunder: Adalah pengobatan penyakit tahap dini.

5. Preventif Tersier: Adalah diagnosa penyakit, pembuatan diagnosa dan pengobatan. 


\section{Kuratif. Adalah penyembuhan suatu penyakit}

7. Rehabilitasi. Adalah proses memulihkan dan proses mengobati.

b. Kepuasan Pasien

Kepuasan pasien merupakan perasaan yang dimiliki pasien dan timbul sebagai hasil dari kinerja layanan kesehatan setelah pasien membandingkannya dengan apa yang diharapkan. Hasil tersebut berupa respon dari pasien terhadap pelayanan kesehatan yang diterima secara nyata. Pelayanan kesehatan yang dimaksud dalam penelitian ini yakni pelayanan keperawatan. Pelayanan keperawatan yang diterima oleh pasien ternyata lebih buruk dari harapan pasien, maka pasien tersebut merasa tidak puas karena merasa kecewa. Apabila pelayanan keperawatan yang diterima oleh pasien ternyata sebanding dengan harapan pasien maka pasien merasa puas (senang). Kepuasan pasien adalah suatu prioritas yang akan membantu perawat dalam memberikan pelayanan keperawatan agar pasien mau berparisipasi selama perawatan.

\section{Klasifikasi kepuasan}

\section{Sangat memuaskan}

Diartikan sebagai ukuran subjektif hasil penilaian perasaan pasien yang menggambarkan pelayanan kesehatan sepenuhnya atau sebagian besar sesuai kebutuhan atau keinginan pasien, seperti sangat bersih (untuk prasarana), sangat ramah (untuk hubungan dengan dokter atau perawat), atau sangat cepat (untuk proses administrasi), yang seluruhnya menggambarkan tingkat kualitas pelayanan yang paling tinggi.

\section{Memuaskan}

Diartikan sebagai ukuran subjektif hasil penilaian perasaan pasien, yang menggambarkan pelayanan kesehatan tidak sepenuhnya atau sebagian sesuai kebutuhan atau keinginan seperti tidak terlalu bersih (untuk sarana), agak kurang cepat (proses administrasi), atau kurang ramah, yang seluruhnya ini menggambarkan tingkat kualitas yang kategori sedang.

3. Tidak memuaskan

Diartikan sebagai ukuran subjektif hasil penilaian perasaan pasien rendah, yang menggambarkan pelayanan kesehatan tidak sesuai kebutuhan atau keinginan seperti tidak terlalu bersih (untuk sarana), agak lambat (untuk proses administrasi), atau tidak ramah. 


\section{Sangat tidak memuaskan.}

Diartikan sebagai ukuran subjektif hasil penilaian perasaan pasien yang rendah, menggambarkan pelayanan kesehatan tidak sesuai kebutuhan atau keinginan seperti tidak bersih (untuk sarana), lambat (untuk proses administrasi), dan tidak ramah. Seluruh hal ini menggambarkan tingkat kualitas yang kategori paling rendah.

\section{PENUTUP}

Kesimpulan dan Saran

Rumah sakit merupakan suatu jasa pemberi layanan kesehatan yang harus mampu memberikan kepuasan pada para penggunanya. Rumah Sakit harus memberikan pelayanan yang terbaik, sehingga pengguna mendapatkan kepuasan. Pelayanan keperawatan adalah salah satu aspek yang mempengaruhi kepuasan pasien bagi pengguna fasilitas pelayanan kesehatan di rumah sakit. Tujuan penelitian ini adalah untuk mengetahui tingkat kepuasan pasien terhadap pelayanan asuhan keperawatan.

Oleh karena itu profesionalisme sangat berhubungan dan mempengaruhi tingkat kepuasan pasien. Dengan perawat menjalankan profesionalisme secara baik, hal tersebut sudah memberikan kebermanfaatan yang baik bagi pasien. Sudah seharusnya perawat memiliki sikap profesionalisme yang baik guna menunjukan tanggung jawabnya terhadap profesi yang diembannya. Selain itu perawat juga harus dapat mengembangkan dan mempertahankan profesionalismenya agar secara terus menerus dapat memberikan pelayanan yang baik untuk pasien. 


\section{REFERENSI}

Suryanto, Sutomo, Setyawati, (2011), Kepuasan Kerja dan Persepsi Perawat tentang Kepemimpinan dengan Kinerja Perawat Pasca Sertifikasi ISO 9001/2008, Jurnal Manajemen Pelayanan Kesehatan Vol. 14 No. 1 Maret 2011: 37.

Prayitno Timbul, Saryono, Sarwono,(2011) Hubungan Lama Kerja Perawat dengan Kepuasan Pasien Pasca Bedah di Ruang Perawatan Bedah RS PKU Muhammadiyah Gombong, Jurnal IImiah Kesehatan Keperawatan, Vol. 7, No. 2, Juni 2011 : 111

Bararah, Taqiyyah. 2013. Asuhan Keperawatan Panduan Lengkap Menjadi Perawat Profesional Jilid 1. Jakarta : Prestasi Pustakaraya

Departemen Kesehatan RI, Pedoman Uraian Tugas Tenaga Perawat Di Rumah Sakit, Jakarta 2012, Departemen Kesehatan RI dan WHO.

Hardinna Sosila Wati. 2013. "Hubungan Penerapan Patient Safety dengan Mutu pelayanan pada pasien Rawat Inap di Rumah Sakit Daya Makasar Tahun 2012"

Wahid, Nurul. 2012. Pengantar Dokumentasi Proses Keperawatan. Jakarta : Trans Media Jakarta.

Suarli S. 2010. Manajemen Keperawatan dengan Pendekatan Praktis. Jakarta: PT Penerbit Erlangga.

Efa Novita T,(2011) Widjajaning Budi, Gartinia Nurcholis, Hubungan Antara Motivasi Kerja Perawat dengan Kecenderungan Mengalami Burnout pada Perawat di RSUD SeruiPapua, Jurnal, Insan Vol. 13 No. 02, Agustus 2011.

Royani, (2010), Hubungan Sistem Penghargaan dengan Kinerja Perawat dalam Melaksanakan Asuhan Keperawatan di Rumah Sakit Umum Daerah Cilegon Banten, Tesis, Program Pascasarjana Fakultas Ilmu Kesehatan Universitas Indonesia .

Simamora, R. H. (2019). Development of Guidelines for Applying appropriate Patient Identification to Achieve Patient Safety Goal INC2019 12th International Nursing Conference. 2019.10455 - 455 (1 pages) UCI(KEPA) : I410-ECN-0101-2019-512001224337

Simamora. R. H. (2008) The correlation of ward chief's giving direction and command and the performance of on-duty nurses at Jember dr. Subandi general hospital inpatient wards. jurnal Administrasi dan Kebijakan Kesehatan, (https://fkm.unair.ac.id/jurnaladministr) 
$\nabla$ Edit dengan WPS Office 